\title{
The Present Situation and Countermeasure for Culturing of Innovation Capability of Graduated Students
}

\author{
Weilin Shi ${ }^{\mathrm{a}}$ and Xiying Ma ${ }^{\mathrm{b} *}$ \\ Suzhou University of Science and Technology, $1^{\#}$ Kerui Road, Suzhou 215009, Jiangsu, China

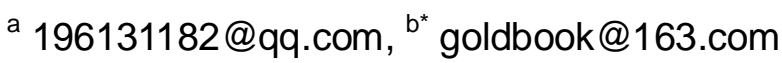

Keywords: Science and engineer graduated students; Innovation capability; Present situation; Approach

\begin{abstract}
In present knowledge and economy society, it is necessary to strength the innovation capability cultivation of graduated students. These years, graduate education is expanded largely in China. Some heavy problems bring out along with the enlarged enrollment scale. First, guidance professor is in deficiency for quite a few colleges and universities. Second, the specialty foundation of the enrolled students decreases much a lot. These problems lead a tendency of graduated education to undergraduate education, and the capacity graduates for independent engaged in scientific pursuit is limited also. Now, the ministry of education and many colleges and universities become aware of this phenomenon, and have made a series of documents and related measures. Therefore, it has a significant meaning for improving the quality to strengthen the innovation capability cultivation of graduates.
\end{abstract}

\section{Introduction}

The creativity capability of students is a versatile and comprehensive expression. Generally, talents of creative ability should have strong creative spirit and operating ability in scientific research and practice in addition to with a solid professional foundation, broad knowledge, incisive mind and flexible adaptability[1]. Moreover, they should have high sensitivity and insight, also have ability of independent thinking and realistic scientific attitude. As the world manufacturing center, China has proposed a strategic target to develop an innovation-oriented country[2]. It must needs to realize a change from manufacturing giant to manufacturing power. To complete the strategic orientation, it needs a large number of high-quality innovative talents. Graduate education has been an important component part higher education and a major route for training high-level professional and technical personnel[3-5]. Graduates have been a backbone in high speed science and technology development in the new century[6]. Therefore, we must reforms and develop our graduate education. The graduate education must emphasis the cultivation of innovative consciousness and innovative abilities specially.

\section{The Innovation Situation in Science and Engineering Graduates}

Currently, the number of graduates increased largely but their creativity is in deficiency in China. There are main three reasons: (1) the professional theoretical knowledge is not advanced. Since many training institutions of graduate do not pay much attention to specialized theory learning, some courses are obviously outdated, textbooks are updating slowly, and students are lack of initiative. (2) The rate of graduates participating to research practice is low. According to some surveyed data, the participation in total graduates to fundamental research, applied research and experimental research is only $21.73 \%$. It is only $5.11 \%$ to application of research and development and other services of science and technology. It can be seen that most graduates did not directly participate in actual researches, while a majority of them were engaged in virtual research in laboratory or office. (3) The academic achievements at higher level is few, and the cited rate of papers is far lower the average of international. The reason caused low innovative ability of graduates is various. It is partly rely on graduates themselves, and partly influenced by training institutions, supervisors, and the general mood of society[7]. 
Problems from Graduate Enrollment Expansion. The training scale of graduate is expanded rapidly in China recent years. The number of graduate increases significantly, leading to a series of new problems came out[8]. First, Many students are not interest in learning and research completely since a large proportion of students selecting to take part in the entrance exams for graduate are under employment pressure. The graduate diploma is only seen as a career stepping stone. It makes the climate for learning is impetuous, the academic grounding in basic skills is weak, and students more frequently can not finish thesis independently. Secondly, the proportion of tutor and student is in high disproportion. It is usual for a tutor instructor several or even dozens of students, leading to teachers too busy to attend all students. Students can not receive adequate guidance, the quality of scientific research and papers decline. On one hand, students do not dive into research; on the other hand, education resources can fully satisfy to student's needs. These reasons of subjective and objective make the innovative ability of graduates greatly reduce.

Lack of Innovation of Courses and Mode. Courses of science and engineer highly rely on practical laboratory. Knowledge on books is essential but cannot stain on understanding or even imagined [9]. More important, it is need to specific experience in experimental. However, many training institutes of graduate students pay little attention to courses setting on common basis experiment and public technology for science engineering graduate student ever since a long time ago. The teaching system and plan are set less reasonable, and the contents are old can not keep up with the demand of the latest development and unable to meet the needs of scientific research and engineering development.

Low Research Participation. According to the statistical analysis data of graduates participation in scientific practice from universities affiliated the education ministry of China, students joined in the projects of research and development are not in a wide range. And they take part in scientific services and practice activities are strikingly few.

\section{Countermeasures for Improving Innovative Ability Graduate}

Optimize the Course Plan and Content. Graduates must have a broad basic theory and systemic expertise, and with an ability of independent study and expression [10]. In setting of their courses, we tried to choose some courses that closely related to hot research points of today. On the contents, we made a large reform also. The content of textbooks and the newest research results are given. For instance, in chapter of silicon solar cell in 《optoelectronic technology》, the contents of single crystal, polycrystal and amorphous silicon solar cells, included all kinds of thin film solar cell and organic cell, and their status and trends of solar cells are given. This makes the students easily find out the recent hot research points, and select their research direction of interest combined with their research fields.

Paying Attention to Data Materials Searching. It needs searching a lot of data materials before and after the research projects, experiment data processing, and thesis writing in time and continuously, specially important for the former steps. In fact, research works is just started from consulting information materials in domestic and foreign largely and systemically. It is said the experiment work have down a half if the documents are collected completely. Graduate students in our school generally select their interest research project based on the programs of their instructors. The method of collecting date materials roughly read 15-20 papers, focusing on their abstract, introduction and construction, understanding the meaning and backdrop of the project, and making clear the reason the authors to carried out the research, finding out the research solution, method, and results. If the search work is behind determining a project that usually come from some problem in producing and experiments, or from the outstanding hard problems. In this case, the searching process must have strong points. Students should write period conclusion after finished each stage work that is base materials for their thesis.

Participating Research Programs of Teachers. The research direction of students is determined by their instructor according the progress and needs of their programs. The students determine their research method, approach and technical route based on searching documents. Then 
the plan is supplied and perfected by their instructors. Next, the students systemically carry out the research work in all aspects instructed by the tutors. For example, synthesis some materials, the influence factors to optoelectronic properties of materials, such as temperature, pressure, and time etc, are determined firstly. For each factor, it needs systemically study then can obtain some rules.

Training the Innovative Ability. The innovative thinking and ability of students are cultivated based on the students with some research ability and integrated capability by using the studied knowledge. For instance, graphene is a hot research material at home and abroad recently. It is composed of a single carbon layer that has superior fast electron mobility, which can be used to make superior fast transistor. At the same time, graphene has strong optical transmission rate that can be used to make as transparency electrode for solar cell, LED devices, and panel display devices. We guided students to think other materials with same crystal structure, such as $\mathrm{MoS}_{2}, \mathrm{PbS}$ etc, whether have such properties or not. The students will open their thoughts and research method through compared these materials to graphene. After above steps of comparing and reasoning, the innovative thinking of students is enhanced, and finally arrived to the cultivating of the innovative ability.

Self-cultivation of Scientific Research and Innovative Ability. There are many scientific programs of students offered by universities, and ministry of education in China, students write applications to apply these project instructed by tutors. Students determine a research program based on above works and searching documents. And propose the research contents and objects, research plan and route after cooperated with their members. These steps are the process of self-cultivate for scientific research and innovative ability. It is an important change, the program previously offer by their supervise change to find it by themselves, they changes the role from passive to active. It is also a change of quantity to quality; realize the improvement of innovative ability.

\section{Summary}

We present the situation of innovation level in science and engineering of graduates in China, and purpose some approaches and methods for raising graduates' research and innovative competence. Education institutes reform the setting of courses and content. Graduates actively take in scientific program from searching the documents, designing the experiments, datum processing, and thesis writing and submission steps. In addition to graduates think independently, address the innovative consciousness, pay attention to the accumulated and summarized, and focus on the change and cooperation of the members.

\section{References}

[1] J. Wu, H. Zhu, J. li, A revelation of graduate education of United States for the innovative ability cultivation of graduates in China. Journal of railway vocational and technical college of Shijiazhuang, 3 ( 2008) 87-91.

[2] X. Wu, Y. Yang, F. Chen, Production, teaching \& research and quality education cultivation mode of engineering postgraduates, Higher Education of Chemical Engineering. 2 (2002) 78-80.

[3] X. Zhu, H. Guo, Higher Education of cultivation innovative ability in Integration with engineering graduates, J. of Yangtze University, 1 (2008) 117-119.

[4] H. Dong, J. Li, Analysis and Reflection on innovative education of science and engineering graduate students, Chemical higher education, 2 (2005), 111-113.

[5] M. Zhang, STS education and training of comprehensive innovative ability of science and engineering graduate students,, Science Popularization,5 (2011) 47-53.

[6] L.Zhou, L. Liu, On the role of humanistic quality education in the cultivation of innovative ability of science and engineering graduate students, Chemical higher education,3 (2014) 47-55. 
[7] W. Wang, J. Li, W. Zahng, Analysis of creative ability of liberal arts graduate students in science and Engineering Universities from a comparative perspective, Heilongjiang Researches on Higher Education, 9 (2012) 159-161.

[8] X. Zhang, J. Chen, Study on the curriculum of graduate education in Sino US Polytechnic University, Foreign education research,2 (2008) 61-66.

[9]Y. Zhang, X. Fang, Science and engineering degree, graduate student, intellectual property education, Chinese University Science and technology, 5(2014) 66-67.

[10]G. Nang, Practice and Reflection on teaching reform of graduate students in science and Engineering Universities, Science and technology economy, 24 (2016) 147-148. 